ARTICLE

\title{
Large Stokes shift fluorescence activation in an RNA aptamer by intermolecular proton transfer to guanine
}

\author{
Mateusz Mieczkowski ${ }^{1,2,3,7}$, Christian Steinmetzger ${ }^{1,5,7}$, Irene Bessi ${ }^{1}$, Ann-Kathrin Lenz ${ }^{1}$, Alexander Schmiedel ${ }^{1}$, \\ Marco Holzapfel ${ }^{1}$, Christoph Lambert (10 ${ }^{1,4 凶}$, Vladimir Pena ${ }^{3,6 凶}$ \& Claudia Höbartner (1) 1,2,4凶
}

Fluorogenic RNA aptamers are synthetic functional RNAs that specifically bind and activate conditional fluorophores. The Chili RNA aptamer mimics large Stokes shift fluorescent proteins and exhibits high affinity for 3,5-dimethoxy-4-hydroxybenzylidene imidazolone (DMHBI) derivatives to elicit green or red fluorescence emission. Here, we elucidate the structural and mechanistic basis of fluorescence activation by crystallography and timeresolved optical spectroscopy. Two co-crystal structures of the Chili RNA with positively charged $\mathrm{DMHBO}^{+}$and $\mathrm{DMHBI}^{+}$ligands revealed a $\mathrm{G}$-quadruplex and a trans-sugar-sugar edge $G: G$ base pair that immobilize the ligand by $\pi-\pi$ stacking. A Watson-Crick $G: C$ base pair in the fluorophore binding site establishes a short hydrogen bond between the N7 of guanine and the phenolic $\mathrm{OH}$ of the ligand. Ultrafast excited state proton transfer (ESPT) from the neutral chromophore to the RNA was found with a time constant of $130 \mathrm{fs}$ and revealed the mode of action of the large Stokes shift fluorogenic RNA aptamer.

\footnotetext{
${ }^{1}$ Julius-Maximilians-Universität Würzburg, Institut für Organische Chemie, Am Hubland, 97074 Würzburg, Germany. ${ }^{2}$ Georg August University School of Science, GGNB Doctoral Program Biomolecules, Justus-von-Liebig-Weg 11, 37077 Göttingen, Germany. ${ }^{3}$ Max Planck Institute for Biophysical Chemistry, Am Fassberg 11, 37077 Göttingen, Germany. ${ }^{4}$ Center for Nanosystems Chemistry, Universität Würzburg, Am Hubland, Würzburg, Germany. ${ }^{5}$ Present address: Karolinska Institute, Stockholm, Sweden. ${ }^{6}$ Present address: Institute of Cancer Research (ICR), London, UK. ${ }^{7}$ These authors contributed equally: Mateusz Mieczkowski, Christian Steinmetzger. ${ }^{凶}$ email: christoph.lambert@uni-wuerzburg.de; vlad.pena@icr.ac.uk; claudia.hoebartner@uni-wuerzburg.de
} 
F luorogenic aptamers specifically activate the fluorescence of conditional fluorophores for RNA imaging and biosensor applications in vitro and in vivo ${ }^{1-3}$. Prominent examples of fluorogenic aptamers include the malachite green aptamer ${ }^{4}$, Spinach ${ }^{5}$, Broccoli $^{6}$, Corn $^{7}$, Chili $^{8}$, Mango $^{9}$, SiRA $^{10}$, Coral $^{11}$, and Pepper $^{12}$ aptamers, which use diverse classes of chromophores that are non-emissive in their free state but display strong fluorescence enhancement upon formation of the aptamer-ligand complex. The class of Spinach, Broccoli, Corn, and Chili are RNA mimics of green fluorescent proteins (GFP) that bind and activate derivatives of 4-hydroxybenzylidene imidazolone (HBI), a smallmolecule analog of the tripeptide chromophore in GFP ${ }^{13}$. Spinach and Broccoli bind the difluorinated ligand DFHBI and its derivatives $5,14,15$, and emulate the deprotonated chromophore and small Stokes shift of the enhanced GFP (eGFP) ${ }^{16}$. The dimeric Corn aptamer activates $\mathrm{DFHO}^{7}$, a spectrally shifted oxime derivative of DFHBI, which resembles the chromophore of the red fluorescent protein DsRed ${ }^{17}$. Chili, on the other hand, is a large Stokes shift fluorogenic RNA aptamer, which was engineered from the dimethoxy-HBI (DMHBI)-binding 13-2 RNA aptamer ${ }^{5}$ by truncation and sequence optimization. The resulting 52 nt Chili RNA preferentially binds and activates the positively charged chromophores $\mathrm{DMHBI}^{+}$and $\mathrm{DMHBO}^{+}(\text {Fig. } 1 \mathrm{a}, \mathrm{b})^{8,18}$ and mimics large Stokes shift fluorescent proteins ${ }^{19}$. In contrast to Spinach, which binds the deprotonated form of DFHBI, Chili exclusively binds the phenol form of DMHBI derivatives but enhances fluorescence of the phenolate forms. The positively charged groups in $\mathrm{DMHBI}^{+}$and $\mathrm{DMHBO}^{+}$substantially enhanced the binding affinity and fluorescence brightness ${ }^{8,18}$.

Understanding the details of fluorescence activation requires knowledge of the underlying three-dimensional RNA structures. The co-crystal structures of Spinach and Corn aptamers in complex with their cognate ligands revealed the presence of Gquadruplex domains that stabilize the fluorophores by stacking

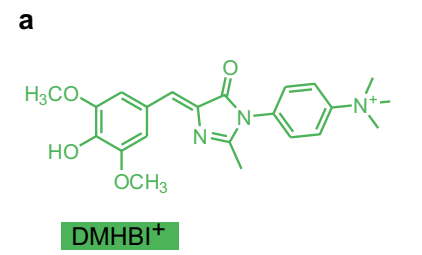

b

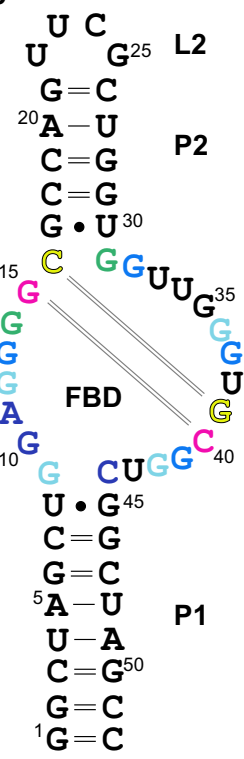

interactions ${ }^{1}$. The binding sites feature complex quadruplex topologies $^{20-22}$ including the formation of a homodimer interface in Corn ${ }^{7}$. G-quadruplexes have also been identified in the Mango aptamer family, which binds and activates the thiazole orange conjugate TO1-Biotin ${ }^{23-25}$. Functional characterization of the Chili RNA has indicated that a G-quadruplex is likely involved in the RNA-ligand interaction 8,18 , consistent with earlier hints obtained for the 13-2 aptamer with $\mathrm{DFHBI}^{20}$. However, the structural and mechanistic basis for ligand binding and deprotonation that cause the large Stokes shift in the fluorescence emission of the Chili aptamer have so far remained elusive.

Here we report the co-crystal structures of Chili bound to $\mathrm{DMHBO}^{+}$and $\mathrm{DMHBI}^{+}$at a resolution of 2.25 and $2.95 \AA$, respectively. A two-tiered G-quadruplex forms the core of the binding site and supports the ligand, which is anchored by an interaction of the oxime moiety with the RNA backbone. The methoxyphenol binding site is stabilized by metal ion coordination and by a short hydrogen bond between the $\mathrm{OH}$ of the ligand and the N7 of a guanine residue in an unpredicted Watson-Crick base pair. The structure suggests a model for the excited state proton transfer (ESPT) that is supported by time-resolved spectroscopy. These insights enabled structure-guided miniaturization of the Chili aptamer and will aid future engineering of fluorogenic modules for sensors and imaging applications.

\section{Results}

Overall structure of the Chili RNA aptamer bound to $\mathrm{DMHBO}^{+}$ and $\mathrm{DMHBI}^{+}$. The 52-nt Chili RNA aptamer was co-crystallized with two of its cognate ligands, $\mathrm{DMHBO}^{+}$and $\mathrm{DMHBI}^{+}$(Fig. 1a, b). Crystals were grown by hanging-drop vapor diffusion and imaged under a fluorescence microscope (Fig. 1c). Crystals were derivatized with iridium(III) hexammine (by soaking or co-crystallization), experimental phases were obtained by single-wavelength anomalous dispersion (SAD), and the initial models were used for molecular
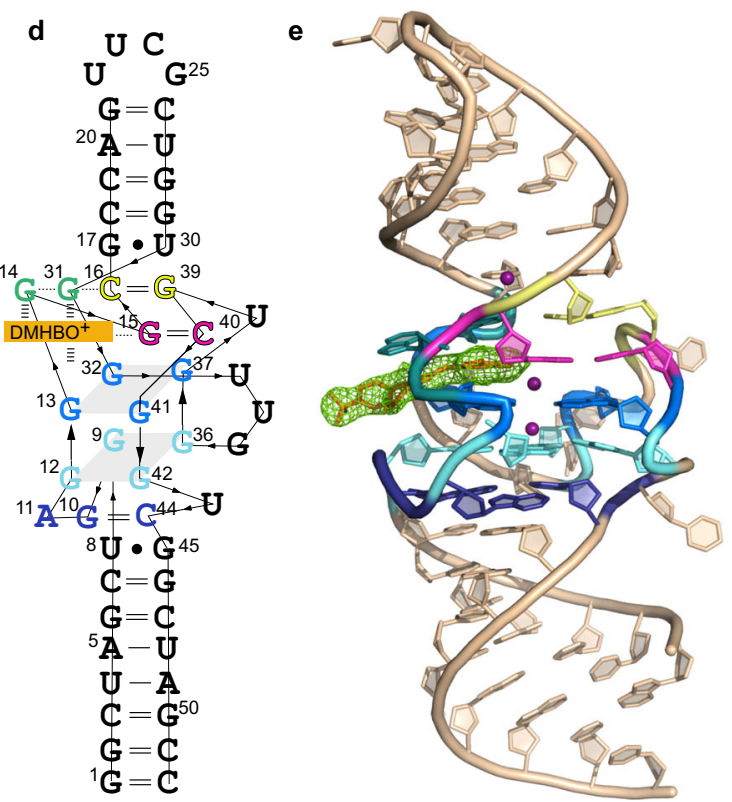

Fig. 1 Overall structure of the Chili-DMHBO ${ }^{+}$and Chili-DMHBI ${ }^{+}$complexes. a Chemical structures of $\mathrm{DMHBO}^{+}$and $\mathrm{DMHBI}^{+}$. b Sequence and secondary structure of the 52-nt Chili RNA. P paired region, L loop, FBD fluorophore binding domain. Nucleotides shown in the same color interact by $\mathrm{H}$ bonding in base pairs (green, pink, and yellow), base triple (dark blue), or G-quartets (light blue and cyan). c Images of representative Chili-DMHBO+ crystals under white light (left) and UV irradiation with a mercury vapor lamp and fluorescence filter set (right). Scale bar: $20 \mu \mathrm{m}$. Images of $n=15$ crystals were taken with similar results. d Tertiary fold diagram of Chili-DMHBO+ ${ }^{+}$. Thin lines with embedded arrows indicate $5^{\prime}-3^{\prime}$ connectivity. e Crystal structure of the Chili-DMHBO${ }^{+}$complex. Color code of nucleotides in the $\mathrm{FBD}$ as in panels $\mathbf{b}$ and $\mathbf{d}$. The green mesh represents the polder omit map of the $\mathrm{DMHBO}^{+}$ ligand contoured at $4 \sigma$. 
replacement (MR) with native datasets. The structure of Chili-DMHBO ${ }^{+}$was refined at a resolution of $2.25 \AA$. Likewise, the structure of Chili-DMHBI ${ }^{+}$was solved by $\mathrm{MR}$ and refined at a resolution of $2.95 \AA$ (Supplementary Table 1). The unbiased electron density map allowed unambiguous tracing of the RNA and revealed the location of the fluorophore in each sample. The crystallographic asymmetric unit (ASU) of the native datasets contained four copies of RNA-ligand complexes (Supplementary Fig. 1), which were superimposable with a root mean square deviation (rmsd) of $0.3 \AA$. The structural features of the $\mathrm{DMHBO}^{+}$and $\mathrm{DMHBI}^{+}$complexes are highly similar (Supplementary Fig. 2).

The Chili RNA folds into a single coaxial helical stack with a length of $\sim 70 \AA$ that contains two A-form duplexes P1 and P2 that are separated by the central fluorophore binding domain (FBD). The basal stem P1 contains 8 bp (nt 1-8 and 45-52), and the apical 5 bp stem P2 (nt 17-21 and 26-30) is closed by the UUCG tetraloop L2 (nt 22-25). The FBD spans nt 9-16 and 31-44 and accommodates the ligand binding site (Fig. 1b, d, e). P1 and P2 each contain a terminal G:U Wobble base pair (U8: G45 and G17:U30, respectively) flanking the FBD. The P1 stem transitions via a base triple into a two-tiered G-quadruplex, which constitutes the core of the FBD. The base triple is composed of G10:C44:A11, in which the Hoogsteen edge of A11 contacts the minor groove sugar edge of the cis Watson-Crick G10:C44 base pair, overall forming six hydrogen bonds. The G-quadruplex is formed by quartet $\mathrm{T} 1$ with guanines G9/G12/G36/G42, and quartet T2 with guanines G13/G32/G37/G41, and is stabilized by a central $\mathrm{K}^{+}$ion. The trinucleotide loop U33-U34-G35 is wellresolved in one of the copies in the ASU and partially disordered in the others. The ligand is immobilized by $\pi$-stacking between an unusual G14:G31 base pair and the T2 quartet. The latter also provides the platform for stacking of the long-range canonical Watson-Crick base pair G15:C40, which is followed by C16:G39 to elongate the stem P2 (Fig. 1d). The G17:U30 wobble base-pair provides the binding site for iridium hexammine in the major groove of the apical A-form helix ${ }^{26}$. The tetraloop L2 adopts a conventional UNCG fold ${ }^{27}$, in which G25 is in syn conformation and the nucleobase forms H-bonds with the ribose edge of U22. Electrostatic interactions of the phosphate backbone of C24 and G25 in L2 with the positively charged trimethylammoniumphenyl side chain of a ligand bound to a neighboring Chili molecule serve as register for the head-to-head orientation of two copies of the RNA-ligand complex in the ASU. An intermolecular H-bond between the $2^{\prime}-\mathrm{OH}$ of G25 with N7 of G14 in the neighboring molecule constitutes an additional inter-subunit contact in the crystal lattice (Supplementary Fig. 3).

Organization of the G-quadruplex core of Chili. The architecture of the two-tiered G-quadruplex core in the Chili aptamer is characterized by three consecutive guanine steps (G12-G13, G36-G37, and G42-G41) with mixed parallel and antiparallel strand orientation, and one nonconsecutive (G9/G32) edge (Figs. 1d, 2a). All of the guanines in the G-quartets are in anti conformation (torsion angle $\chi=-120$ to $-160^{\circ}$ ) with the exception of G32, which has high anti conformation (torsion angle $\chi=-79^{\circ}$ ). The G-quartets T1 and T2 have inverted polarity featuring a partial overlap of the guanine imidazole rings (Fig. 2b, c). The G-quartets of the ligand binding site in the Chili RNA are stabilized by a central octacoordinate $\mathrm{K}^{+}$ion $\left(\mathrm{M}_{\mathrm{A}}\right.$, Fig. $\left.2 \mathrm{c}\right)$ with average $\mathrm{K}^{+}$-guanine-O6 distances of $2.8 \AA$ for $\mathrm{T} 1$ and $3.0 \AA$ for T2. Notably, above the G-quadruplex and along the same central axis, a second $\mathrm{K}^{+}$ion $\left(\mathrm{M}_{\mathrm{B}}\right.$, Fig. $2 \mathrm{~d}$ ) is coordinated to T2 (average $\mathrm{K}^{+}$-guanine-O6 distance of $2.8 \AA$ ), the phenolic hydroxy and one methoxy group of the ligand $(2.8 \AA)$ as well as O6 of G15 (3.1 $\AA$ ). The inter- $\mathrm{K}^{+}$distance is $3.5 \AA$.
Architecture of the chromophore binding site. The $\mathrm{DMHBO}^{+}$ ligand adopts a nonplanar conformation within the binding site with twist and tilt angles of $\varphi=-27^{\circ}$ and $\tau=11^{\circ}$, respectively (Supplementary Fig. 4). The deviation from planarity is primarily dictated by the stacking interactions with the RNA nucleobases. The benzylidene moiety of the ligand stacks on top of G13:G32 of the T2 quartet and G31 in the direction of the apical stem. The imidazolone moiety projects outward from the center of the quadruplex where it is anchored by stacking with G14 (Fig. 2d, e). The G14:G31 base pair is stabilized by a trans sugar-sugar edge (tSS) interaction that is mediated by mutual hydrogen bonds between the $\mathrm{NH}_{2}$ of either guanine and $\mathrm{N} 3 / 2^{\prime}-\mathrm{O}$ of the other guanine nucleotide. G31 is further held in place by a hydrogen bond between its own $\mathrm{O} 6$ and $\mathrm{N} 4$ of $\mathrm{C16}$, which itself is part of a long-range Watson-Crick base pair with G39 (Fig. 2e). The cationic side chain of the ligand is located outside the perimeter of the binding pocket and is twisted at an angle of $60^{\circ}$ with respect to the plane of the imidazolone ring (Fig. $2 \mathrm{~d}, \mathrm{f}$ ).

Besides stacking interactions, the ligands establish polar interactions with the RNA (Fig. 2d). The oxime substituent of $\mathrm{DMHBO}^{+}$ forms two hydrogen bonds with the phosphate backbone at G10 and the 2 '-OH group of G9 (Fig. 2f). These contacts explain the difference in binding affinity between $\mathrm{DMHBO}^{+}\left(K_{\mathrm{D}}=12 \mathrm{nM}\right)$ and $\mathrm{DMHBI}^{+}$ $\left(K_{\mathrm{D}}=65 \mathrm{nM}\right)$, and are likely responsible for the higher thermal stability of the fluorescent Chili-DMHBO ${ }^{+}$complex compared to the Chili-DMHBI ${ }^{+}$complex (see fluorescence melting curves in Supplementary Fig. 5).

Identification of the proton acceptor. In the crystal structure, the phenolic moiety of the ligand is coplanar with the long-range Watson-Crick base pair G15:C40 and forms polar contacts with the metal ion $\mathrm{M}_{\mathrm{B}}$, via the phenolic hydroxy group and one of the methoxy groups. Most notably, the phenolic hydroxy group comes into close contact with N7 of G15 (2.5 $\AA$ O-N distance, Fig. 2d), indicative of a mechanism that governs the protonation state underlying the fluorescent properties of the Chili-DMHBO${ }^{+}$ complex.

At $\mathrm{pH} 7.5$ and in the absence of the Chili RNA, $80 \%$ of $\mathrm{DMHBO}^{+}$is in the phenolate form exhibiting an absorption maximum at $555 \mathrm{~nm}$ (the $\mathrm{p} K_{\mathrm{a}}$ for the phenol/phenolate equilibrium of $\mathrm{DMHBO}^{+}$is 6.9 , Supplementary Fig. 6. $)^{8}$ Upon binding of $\mathrm{DMHBO}^{+}$to the Chili RNA, the UV/Vis spectrum showed only an absorption maximum of $456 \mathrm{~nm}$, indicating a shift of the equilibrium to the protonated phenol form upon formation of the RNA-ligand complex. The selectivity of the folded RNA aptamer for the protonated form of $\mathrm{DMHBO}^{+}$can be visually observed as a temperature-dependent colour change from purple to yellow upon cooling of the sample (Fig. 3b, c). This process is reversible and upon thermal melting of the RNA structure, $\mathrm{DMHBO}^{+}$is released, reverting the color change. In the absence of RNA, there is no temperature-dependent change in the phenol/phenolate equilibrium, and the absorption maximum of the free phenol form is $20 \mathrm{~nm}$ blue-shifted compared to the bound state. Upon excitation at $456 \mathrm{~nm}$, steady-state fluorescence emission of the Chili-DMHBO ${ }^{+}$complex was observed exclusively from the phenolate form of the ligand, giving rise to the large Stokes shift of $136 \mathrm{~nm}\left(4800 \mathrm{~cm}^{-1}\right)$.

The same magnitude of the Stokes shift was observed when the G-quadruplex-stabilizing $\mathrm{K}^{+}$was replaced by $\mathrm{Tl}^{+}$or by $\mathrm{Na}^{+}$ (Supplementary Fig. 7). With $\mathrm{Tl}^{+}$, the fluorescence intensity was preserved, while $\mathrm{Na}^{+}$gave only $25 \%$ residual intensity, which was partially recovered by supplementing $\mathrm{Na}^{+}$with divalent $\mathrm{Mg}^{2+}$. In contrast, the addition of $\mathrm{Sr}^{2+}$ or $\mathrm{Ba}^{2+}$ caused a bathochromic shift of both excitation and emission maxima by $16-18 \mathrm{~nm}$ only in the presence of $\mathrm{Na}^{+}$. The same trend was observed for Chili- 
a

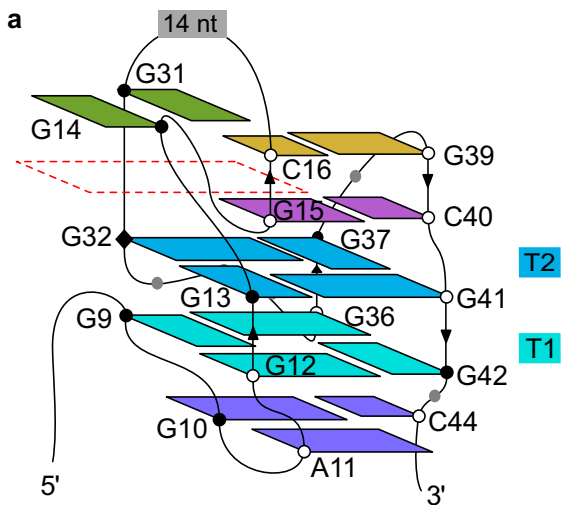

C
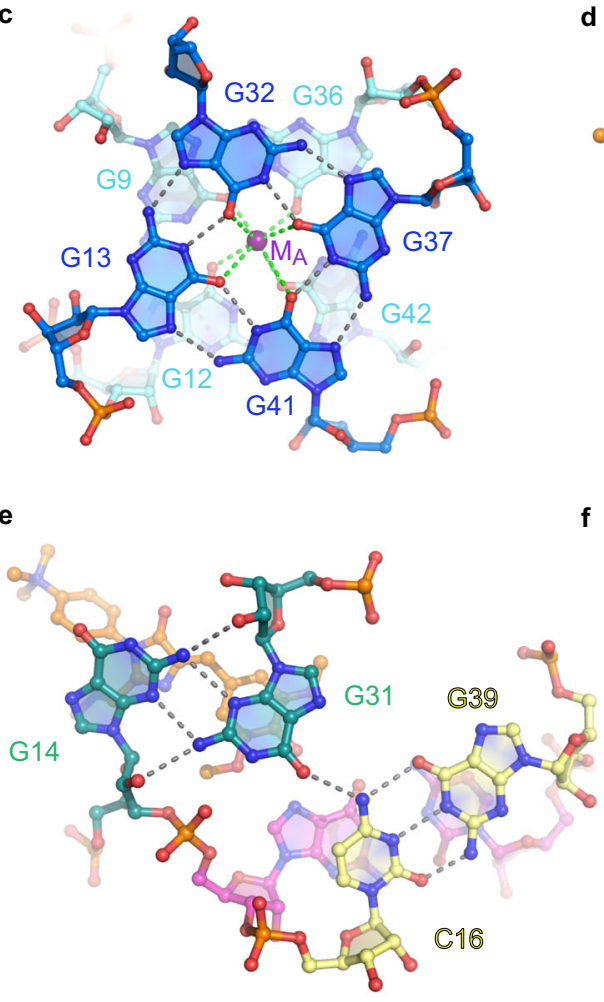

b

d
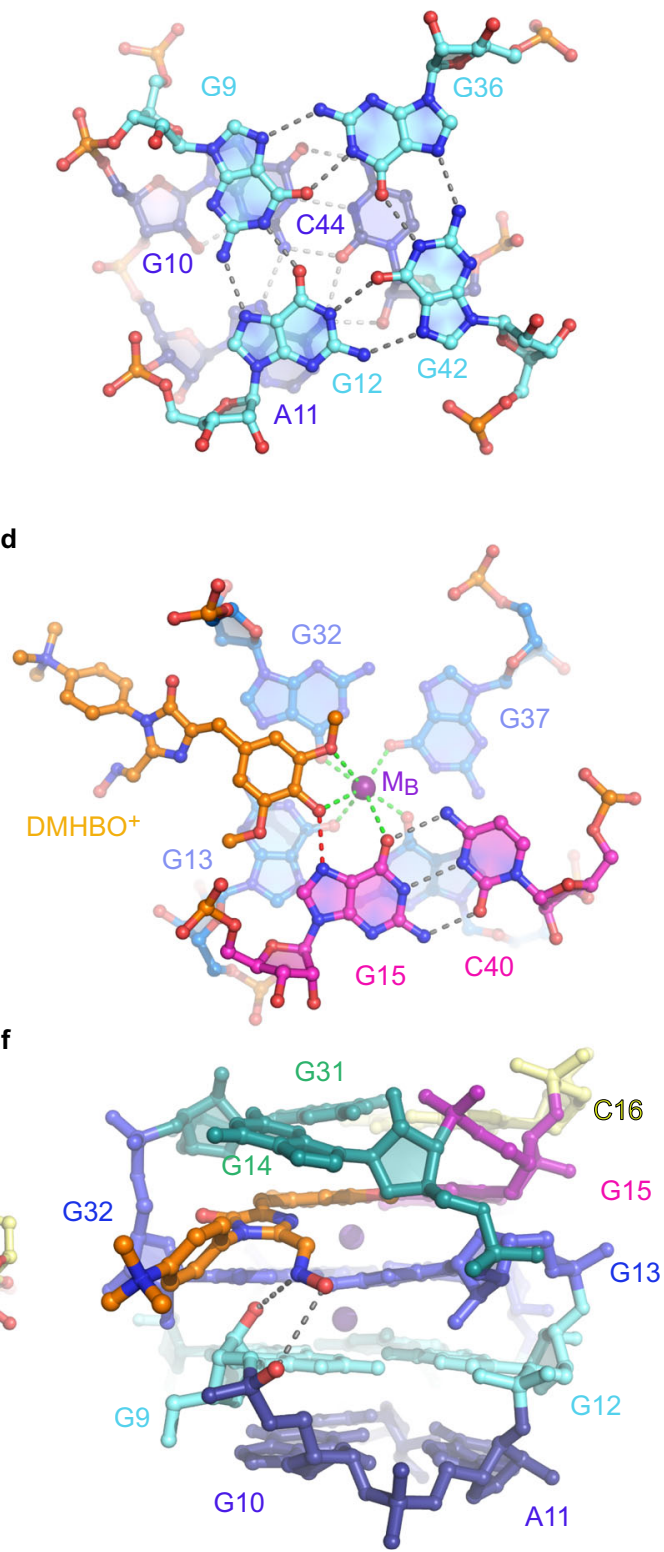

Fig. 2 Organization of the G-quadruplex and ligand binding site of the Chili aptamer. a Schematic representation of the connectivity and stereochemistry in the Chili aptamer core. White and black circles denote C3'-endo and C2'-endo ribose puckers, respectively. Black outline denotes anti conformation (all G's in T1 and T2 are anti, except G32, which is high anti, as denoted by black diamond). The position of the ligand is outlined with the red dashed line. The color code of the nucleobases is as in Fig. 1 and is also used in panels b-f. b G-quartet T1 and the G10:C44:A11 base triple. c T1 and T2 with the central potassium ion $M_{A}$, showing opposite polarity of the quartets with partial 5-5 stacking geometry. Gray and green dashed lines represent hydrogen-bonding and inner-sphere cation coordination, respectively. $\mathbf{d}$ The $\mathrm{DMHBO}^{+}$ligand is stacked on $\mathrm{G}$-quartet $\mathrm{T} 2$ and coordinated with potassium ion $\mathrm{M}_{\mathrm{B}}$ and the $\mathrm{G} 15$ : C40 base pair. The red dashed line represents a $\mathrm{H}$-bond from the hydroxy group of the ligand to N7 of G15. e A trans sugar-sugar edge (tSS) base pair of $\mathrm{G} 14$ and $\mathrm{G} 31$ stabilizes $\mathrm{DMHBO}^{+}$via $\pi$-stacking interactions. $\mathrm{O} 6$ of $\mathrm{G} 31$ forms an additional hydrogen bond with the amino group of C16 in the C16:G39 base pair. $\mathbf{f}$ Stick representation of the ligand binding site showing hydrogen bonding interactions between the oxime moiety of the ligand and the RNA backbone.

$\mathrm{DMHBI}^{+}$, which showed 6-8 $\mathrm{nm}$ blue-shifted emission maxima with $\mathrm{Na}^{+} / \mathrm{Sr}^{2+}$ and $\mathrm{Na}^{+} / \mathrm{Ba}^{2+}$, but not when the $\mathrm{K}^{+}$solution was supplemented with the heavier divalent metal ions $\mathrm{Sr}^{2+}, \mathrm{Ba}^{2+}$, or $\mathrm{Mn}^{2+}$ (Supplementary Fig. 8) ${ }^{18}$. These results suggest that $\mathrm{Na}^{+}$is less tightly bound than $\mathrm{K}^{+}$and can be replaced by divalent metal ions to modulate the electronic coupling with the RNA-ligand complex.

In addition to ligand coordination, metal ion $\mathrm{M}_{\mathrm{B}}$ contacts the G15:C40 base pair in the FBD. Preliminary 2D NMR experiments of the Chili-DMHBI ${ }^{+}$complex in $\mathrm{K}^{+} / \mathrm{Mg}^{2+}$ solution revealed an unusual signal at a proton chemical shift of $8.6 \mathrm{ppm}$ and ${ }^{15} \mathrm{~N}$ chemical shift of $142 \mathrm{ppm}$ (Supplementary Fig. 9). The resonance unambiguously arises from an exchangeable proton of a guanine but does not belong to a shifted N1 imino proton of a canonical G:C Watson-Crick base pair. Together with the crystal structure, these results suggest that N7 of G15 participates in an ESPT mechanism.

To confirm the involvement of N7 of G15 in ligand binding and ESPT, we performed atomic mutagenesis and prepared a Chili RNA mutant containing 7 -deazaguanine $\left(c^{7} \mathrm{G}\right)$ at position 
a

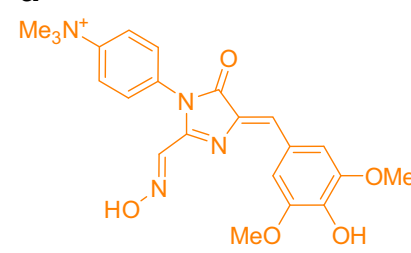

b 0.20
0.15

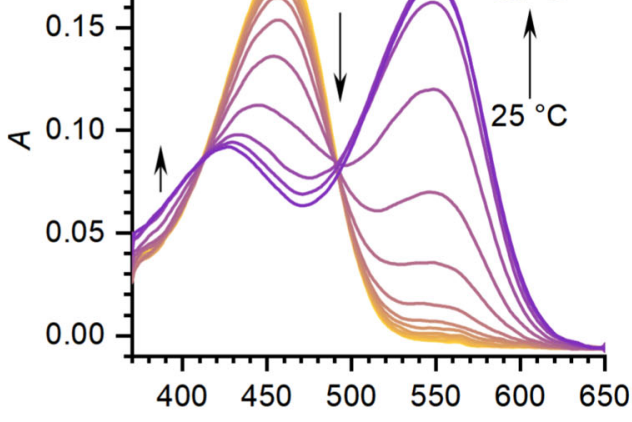

$\lambda(\mathrm{nm})$

C
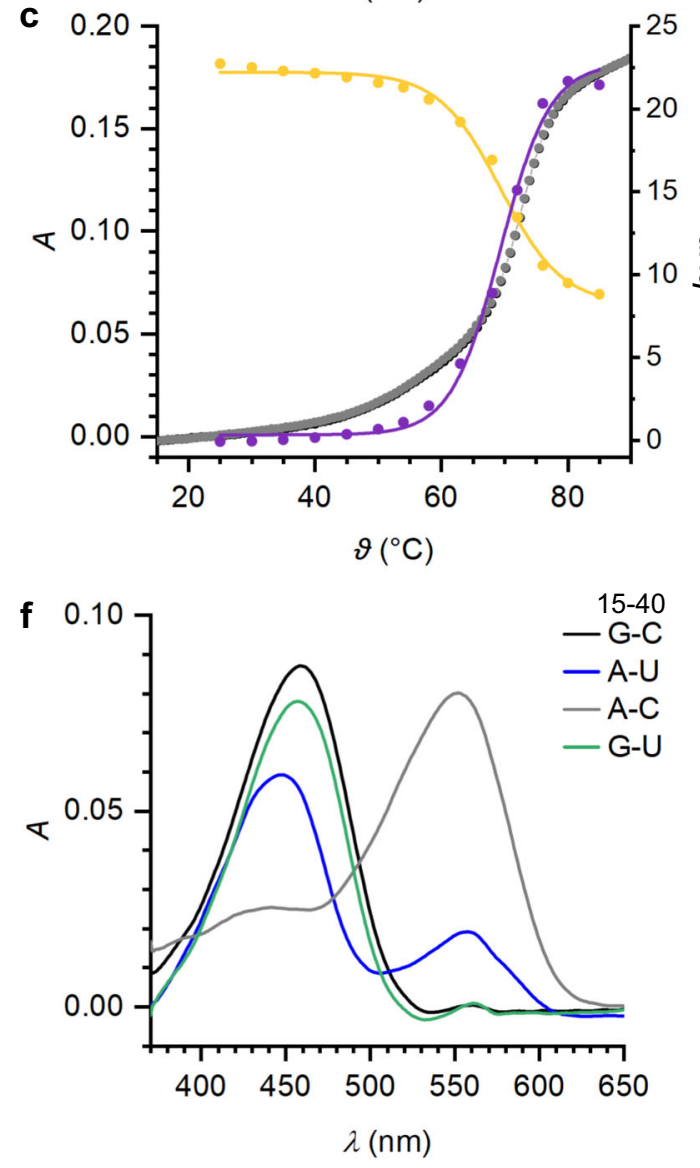

15. Removal of the proposed proton acceptor abrogated the ability to stabilize the protonated $\mathrm{DMHBO}^{+}$ligand and resulted in complete loss of fluorescence activation (Fig. 3d, e, g). To confirm this result, the recently described fluorescent 4cyanoindol ribonucleoside $(\mathrm{r} 4 \mathrm{CI})$ was incorporated at positions 34 or 46 of the Chili RNA, where it reported on ligand binding by serving as a FRET donor to $\mathrm{DMHBO}^{+28}$. No reduction in donor

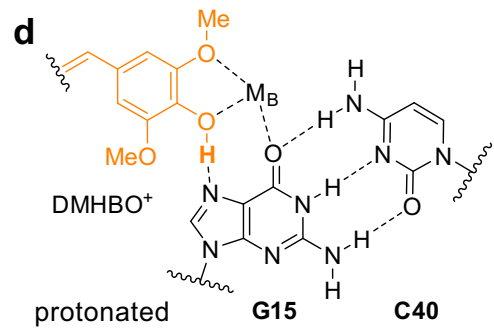

protonated

G15

C40

no $\mathrm{H}$-bond

possible

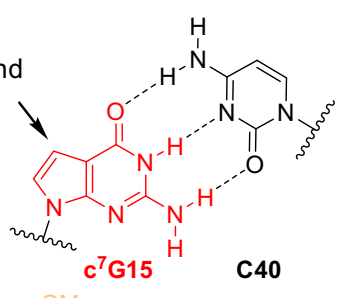

$-45^{\circ} \mathrm{C}$

$-40^{\circ} \mathrm{C}$

$-35^{\circ} \mathrm{C}$

$-30^{\circ} \mathrm{C}$

$-25^{\circ} \mathrm{C}$

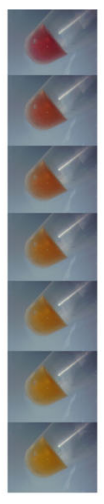

possible<smiles></smiles>

e
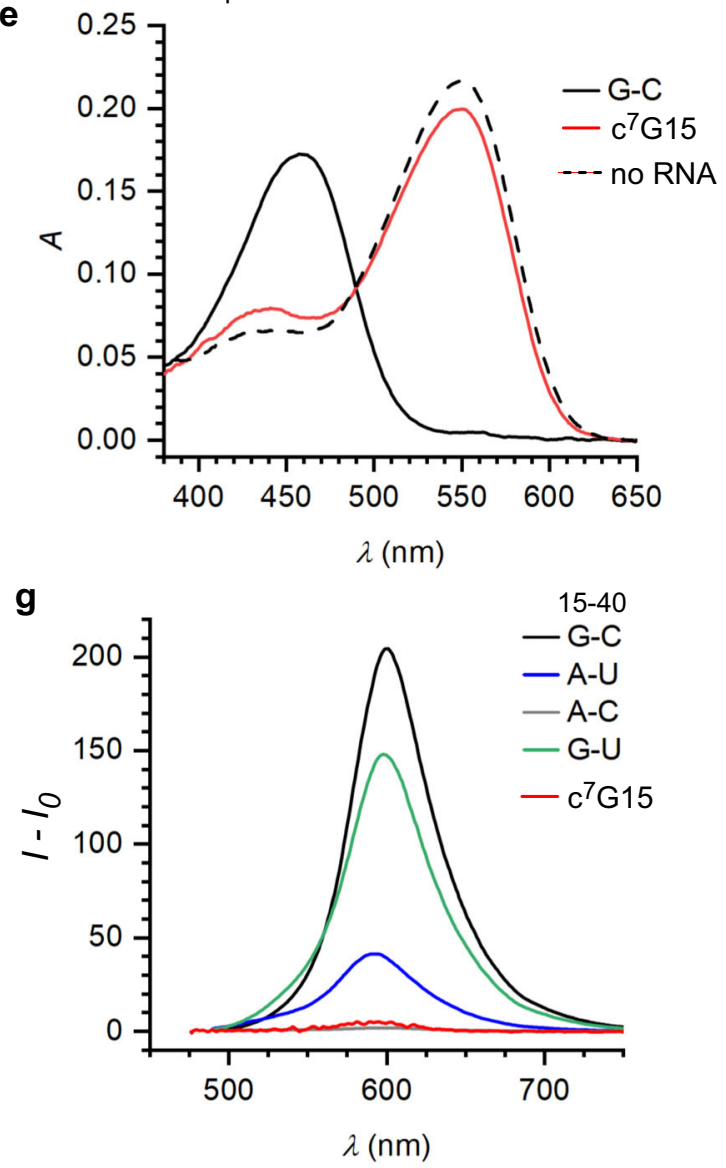

emission due to FRET was observed in $c^{7} \mathrm{G} 15$ mutants of r4CImodified Chili RNA, indicating that N7 of G15 is strictly required for ligand binding (Supplementary Fig. 10).

The role of the G15:C40 base pair was further examined by sitedirected mutagenesis. The $\mathrm{C} 40 \mathrm{U}$ mutation changed the Watson-Crick base pair into a Wobble base pair, resulting in $30 \%$ reduced fluorescence compared to the parent Chili-DMHBO ${ }^{+}$ 
Fig. 3 Chili binds the phenol form of $\mathbf{D M H B O}^{+}$via H-bonding to $\mathbf{N 7}$ of G15. a The phenol/phenolate equilibrium of $\mathrm{DMHBO}^{+}$allows monitoring of RNA folding. $\mathbf{b}$ Temperature-dependent absorbance spectra of the parent Chili RNA-DMHBO ${ }^{+}$complex $(10 \mu M)$ and white light images of $100 \mu M$ solutions upon cooling from $85^{\circ} \mathrm{C}$ to room temperature. c Absorbance $(A)$ at $450 \mathrm{~nm}$ (yellow) and $550 \mathrm{~nm}$ (purple) as a function of temperature. The inflection point at $70^{\circ} \mathrm{C}$ fits well to the reversible thermal melting transition of the RNA monitored at $260 \mathrm{~nm}$ (right axis: hyperchromicity (hyp 260 ), gray). $\mathbf{d} \mathrm{H}-$ bonding between the ligand and N7 of G15 in wt-Chili and selected mutations. e $c^{7}$ G15-modified Chili RNA is not able to shift the phenol/phenolate equilibrium. Absorbance spectra of the parent complex (solid black line) in comparison to free ligand (dashed black line) and with $\mathrm{c}^{7} \mathrm{G}$ RNA mutant (solid red line). $\mathbf{f}$ Absorbance and $\mathbf{g}$ fluorescence spectra of Chili-DMHBO ${ }^{+}$complexes containing point mutations. The C40U mutation (Wobble base pair) is tolerated, while G15A completely disrupts ligand binding and fluorescence. Compensatory mutations of G15:C40 to A15:U40 only partially restore the fluorogenic binding site and result in a blue-shifted absorption maximum. RNA and ligand concentrations are $10 \mu \mathrm{M}$ in $\mathbf{b}$ and $\mathbf{e}$ and $5 \mu \mathrm{M}$ in $\mathbf{f}$ and $\mathbf{g}$

complex (Fig. 3g). The G15A mutation resulted in an A:C mismatch that destroyed the ligand binding site. The compensatory double mutant G15A and C40U was able to bind the ligand but displayed incomplete proton transfer (both before and after excitation), and a $10 \mathrm{~nm}$ blue-shifted absorption maximum of the protonated fraction (Fig. 3d, f). These results strongly support the functional role of the purine Hoogsteen edge as a general base for the proton transfer.

Time-resolved optical spectroscopy. Time-correlated single photon counting (TCSPC) on the ns timescale revealed multiexponential decays for both Chili-DMHBO ${ }^{+}$and Chili-DMHBI ${ }^{+}$complexes but did not resolve the kinetics of proton transfer (Supplementary Fig. 11). Therefore, the photo-induced dynamics of Chili-DMHBO ${ }^{+}$ were studied by a combination of broadband fluorescence upconversion and transient absorption (TA) spectroscopy with fs-time resolution. Upon excitation at $405 \mathrm{~nm}$ with $60 \mathrm{fs}$ pulses a fluorescence band at $510 \mathrm{~nm}$ with $\tau<130 \mathrm{fs}$ was found which is associated with the fluorescence of the protonated species (Fig. 4a and Supplementary Fig. 12). The peak at $560 \mathrm{~nm}$ in this spectrum is already due to the deprotonated chromophore in a vibronically excited state. This band is followed by an intense and broad band at $580 \mathrm{~nm}$ that further shifts to $600 \mathrm{~nm}$ with a number of time constants ranging from 0.78 to $38 \mathrm{ps}$ that reflect the continuous solvent relaxation and possibly also chromophore flattening. The longest-lived band possesses a lifetime of $1.4 \mathrm{~ns}$ and originates from the deprotonated chromophore (Fig. 4b, c). Thus, the unexpectedly short lifetime of $130 \mathrm{fs}$ is attributed to ultrafast ESPT along a pre-organized hydrogen bond. TA spectroscopy confirmed the time constants obtained by fluorescence up-conversion (Supplementary Figs. 13, 14). Fluorescence and TA measurements on Chili-DMHBI ${ }^{+}$gave a similar picture although with transient spectra shifted to shorter wavelengths (Supplementary Figs. 15-17). Again, proton transfer occurred in 120 fs. The results are consistent with proton transfer involving the strong ligandguanine hydrogen bond observed in the crystal structure. The data also explain the fluorescence enhancement by RNA binding, as TA spectroscopy of the free $\mathrm{DMHBO}^{+}$chromophore revealed a very short lifetime of only 17 ps (Supplementary Figs. 18, 19), consistent with the very low quantum yield reported previously ${ }^{8}$. Moreover, the structural and mechanistic insights suggest that the fluorescent properties are dominated by the FBD, and that outside structural elements may be accessible for further engineering of the RNA fluoromodules.

Mutagenesis and minimization of the Chili aptamer. The exact composition and size of the stems P1 and P2 play only subordinate roles for fluorescence activation. Truncation of the basal duplex P1 (mutants P1-1, P1-2, and P1-3) retained more than $80 \%$ of the parent Chili fluorescence intensity with $\mathrm{DMHBI}^{+}$ (Fig. 5a). Additional shortening of the apical hairpin resulted in the $42 \mathrm{nt} \mu \mathrm{Chili}$ aptamer, which activated $\mathrm{DMHBI}^{+}$fluorescence to the same degree as the P1-3 mutant after overnight incubation. The junction between P1 and the FBD is formed by the Wobble base pair U8:G45. The transition mutations U8C or G45A transformed the Wobble base pair into Watson-Crick base pairs C8:G45 or U8:A45 (mutants P1C and P1A, respectively), and resulted in slower maturation of the fluorescent complex compared to the parent Chili. Interestingly, this Wobble base pair directs the folding kinetics independent of the stem length (see G45A mutants P1A-1, P1A-2, and P1A-3). The dissociation constants for $\mu$ Chili or P1A-3 and $\mathrm{DMHBI}^{+}(68$ and $89 \mathrm{nM}$, respectively, Fig. $5 \mathrm{c}$ ) were similar to the $K_{\mathrm{D}}$ of the parent Chili $(65 \mathrm{nM})$. Furthermore, the partially unstructured nucleotides U33-G35 are not essential for the function of the aptamer. Breaking the phosphodiester bond between U34 and G35 while connecting the original $5^{\prime}$ and $3^{\prime}$ ends of P1A-3 by a GGAA tetraloop resulted in a circularly permuted Chili aptamer (Fig. 5b) that retained $75 \%$ of the original P1A fluorescence enhancement. This finding confirms the ligand-induced folding of the quadruplex core, and suggests that the Chili aptamer may be used for fluorescent sensors 29,30 or in RNA nanotechnology 31,32 .

\section{Discussion}

The structure and fluorescence activation mechanism of the Chili aptamer is distinct from other known HBI-binding RNA aptamers like Spinach and Corn. A common feature of most structurally characterized fluorogenic aptamers is a G-quadruplex in the core of the fluorophore binding site $^{1}$, with only few exceptions ${ }^{33}$. The G-quartets stabilize rigid chromophore conformations by stacking interactions that largely govern the photophysical properties ${ }^{34-36}$. Unlike the near-planar fluorinated ligands DFHBI and DFHO in Spinach and Corn $7,20,21$, the fluorophores $\mathrm{DMHBO}^{+}$and $\mathrm{DMHBI}^{+}$in Chili adopt moderately twisted conformations, resembling those found in some LSS fluorescent proteins such as LSSmKate $1^{19}$ and mCRISPred ${ }^{37}$ (Supplementary Fig. 20 and Supplementary Table 3). In Spinach and Corn, the phenolate and imidazolone moieties of the respective ligands are embedded into a hydrogen bonding network with surrounding nucleotides and water molecules (Fig. 6). The oxime side chain of DFHO contacts the Watson-Crick face of an adenine base in the Corn RNA. In contrast, the Chili RNA stabilizes the oxime side chain of $\mathrm{DMHBO}^{+}$via $\mathrm{H}$-bonding to the phosphate backbone. The G-quartet of Chili supports the benzylidene moiety of $\mathrm{DMHBO}^{+}$and the coplanar Watson-Crick base pair G15:C40, which establish the key H-bond between the phenolic hydroxy group of the ligand and the Hoogsteen edge of the Watson-Crick base pair. The central $\mathrm{K}^{+}$ion $\left(\mathrm{M}_{\mathrm{B}}\right)$ also contributes to the orientation and stabilization of the ligand by including a methoxy group in the coordination sphere. Interestingly, $\mathrm{K}^{+}$can be replaced by $\mathrm{Tl}^{+}$with no change in Stokes shift, but is not easily exchanged by divalent metal ions $\left(\mathrm{Mg}^{2+}, \mathrm{Ba}^{2+}\right.$, $\mathrm{Sr}^{2+}$, and $\left.\mathrm{Mn}^{2+}\right)$. For comparison, Spinach places a $\mathrm{K}^{+}$ion next to the phenolate of DFHBI, which can be replaced by $\mathrm{Ba}^{2+20}$.

In Chili, the key ligand-RNA hydrogen bond to the Hoogsteen edge of G15 directly controls the protonation state of the ligand in response to photoexcitation. The Chili RNA aptamer mimics the proton transfer mechanism of LSS fluorescent proteins, in which 

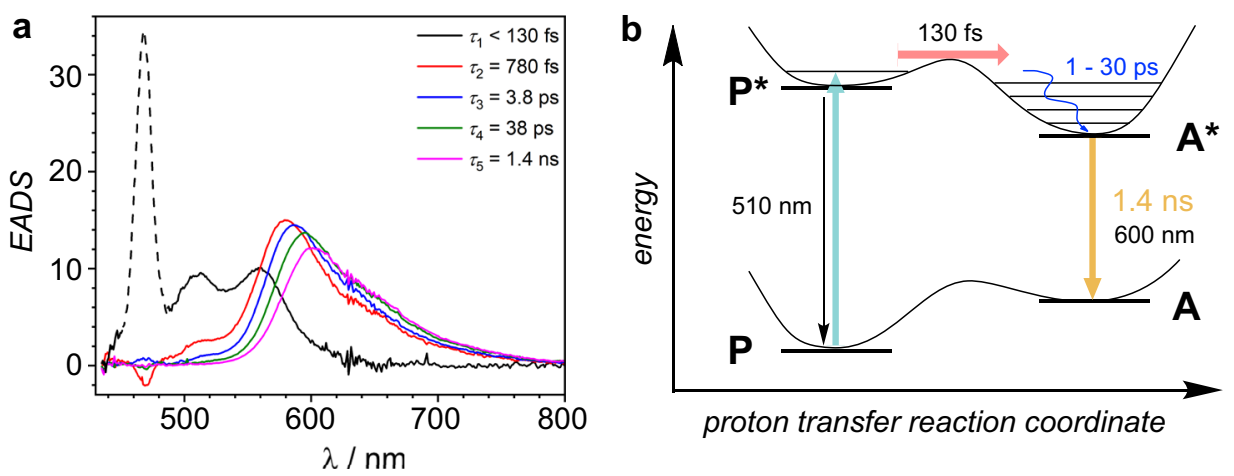

C

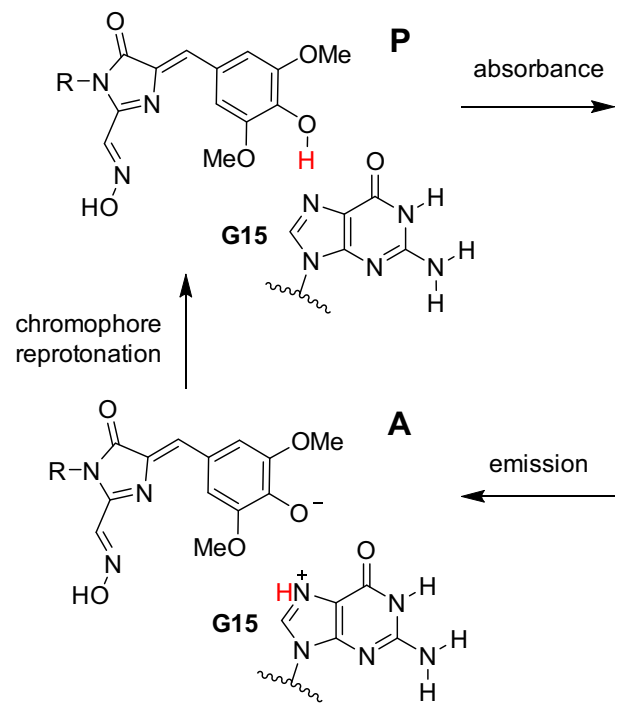<smiles></smiles><smiles>[R]N1C(=O)/C(=C/c2cc(OC)c([O-])c(OC)c2)N=C1/C=N/O</smiles>

Fig. 4 Ultrafast proton transfer in Chili-DMHBO+. a Global deconvolution of time resolved fluorescence spectra from the fluorescence up-conversion measurement of Chili-DMHBO+. The peak at $470 \mathrm{~nm}$ is a Raman signal of water. The black emission spectrum (peaking at $510 \mathrm{~nm}$ ) refers to the protonated form of $\mathrm{DMHBO}^{+}$, the red to magenta spectra to the deprotonated form. The time constants $\tau_{2}-\tau_{4}(0.8-38 \mathrm{ps})$ refer to a continuous dynamic Stokes shift of the emission spectrum caused by solvent and molecular relaxation. The last time constant (1.4 ns) refers to ground state recovery. $\mathbf{b}$ Schematic model of excitation, proton transfer, relaxation, and emission processes observed in (a). For the ESPT a barrier is assumed because of the distinct differences of the emission spectra of both states. c Scheme of the proposed photo cycle in Chili-DMHBO ${ }^{+}$. The neutral chromophore $(P)$ is excited from the ground state. The transition from the excited phenol form $\left(P^{\star}\right)$ to the anionic form $\left(A^{\star}\right)$ occurs through ESPT in 130 fs. After fluorescence emission, the ground state $\mathrm{P}$ is regenerated.

ultrafast ESPT takes place from the chromophore to an acceptor amino acid over a short distance ${ }^{19}$. Our results suggest that the N7 of G15 in the Chili RNA serves as the proton acceptor. The involvement of this nitrogen atom in stabilizing the protonated ligand in the ground state was unequivocally confirmed by atomic mutagenesis. This adds an additional role to the versatile functions of guanine nucleobases found in riboswitches and ribozymes ${ }^{38,39}$.

This work reports the study of ESPT in an RNA environment and allowed probing the RNA-ligand proton transfer dynamics in real time. The proton transfer occurred within $130 \mathrm{fs}$ and is thus much faster than in wt GFP ${ }^{40,41}$, but is comparable to what has been found for GFP mutants with short $\mathrm{H}$-bonds and rewired proton transfer pathways ${ }^{42-44}$.

Engineered fluorescent proteins harness the interplay of chromophore dynamics and protein environment to fine-tune desirable photophysical properties ${ }^{45,46}$. Similarly, fluctuations in RNA structures may influence fluorogenic aptamers. The folding kinetics of the Chili aptamer is strongly dependent on the U8:G45 Wobble base pair, as replacement by a Watson-Crick base pair slowed down the maturation of the fluorescent complex. An influence of quadruplex-flanking base pairs on folding and metal ion dependence has also been reported for Spinach and Broccoli $\operatorname{aptamers}^{47-49}$.

In summary, the structures of the Chili aptamer in complex with the green-emitting $\mathrm{DMHBI}^{+}$and the orange-red-emitting $\mathrm{DMHBO}^{+}$ligands unveiled the mechanism for ligand binding and fluorescence activation. The $\mathrm{H}$-bond interaction between the hydroxyphenyl group and the N7 guanine nitrogen together with the coordination of a potassium ion establishes the Hoogsteen side of a G:C base pair on top of a guanine quartet as a structural motif that facilitates ESPT on the $100 \mathrm{fs}$ timescale. These results further strengthen the view of G-quadruplexes flanked by canonical A-form duplexes as versatile and privileged architectures for fluorescence activation of HBI chromophores.

\section{Methods}

RNA synthesis and complex formation. Unmodified RNAs were prepared by in vitro transcription with T7 RNA polymerase. The DNA templates for in vitro transcription were purchased from Sigma Aldrich or Microsynth. The reaction was performed using synthetic DNA template $(1 \mu \mathrm{M})$, promoter strand $(1 \mu \mathrm{M})$, and inhouse T7 RNA polymerase ${ }^{50}$. The reaction was performed in $8 \mathrm{~mL}$ final volume in the presence of $40 \mathrm{mM}$ Tris- $\mathrm{HCl}, \mathrm{pH} 8.0,30 \mathrm{mM} \mathrm{MgCl} 2,10 \mathrm{mM}$ DTT, $4 \mathrm{mM}$ of each NTP, and $2 \mathrm{mM}$ spermidine. The reaction mixture was incubated at $37^{\circ} \mathrm{C}$ for $4 \mathrm{~h}$, and then stopped by the addition of $100 \mathrm{mM}$ EDTA pH 8.0. The RNA was 
a
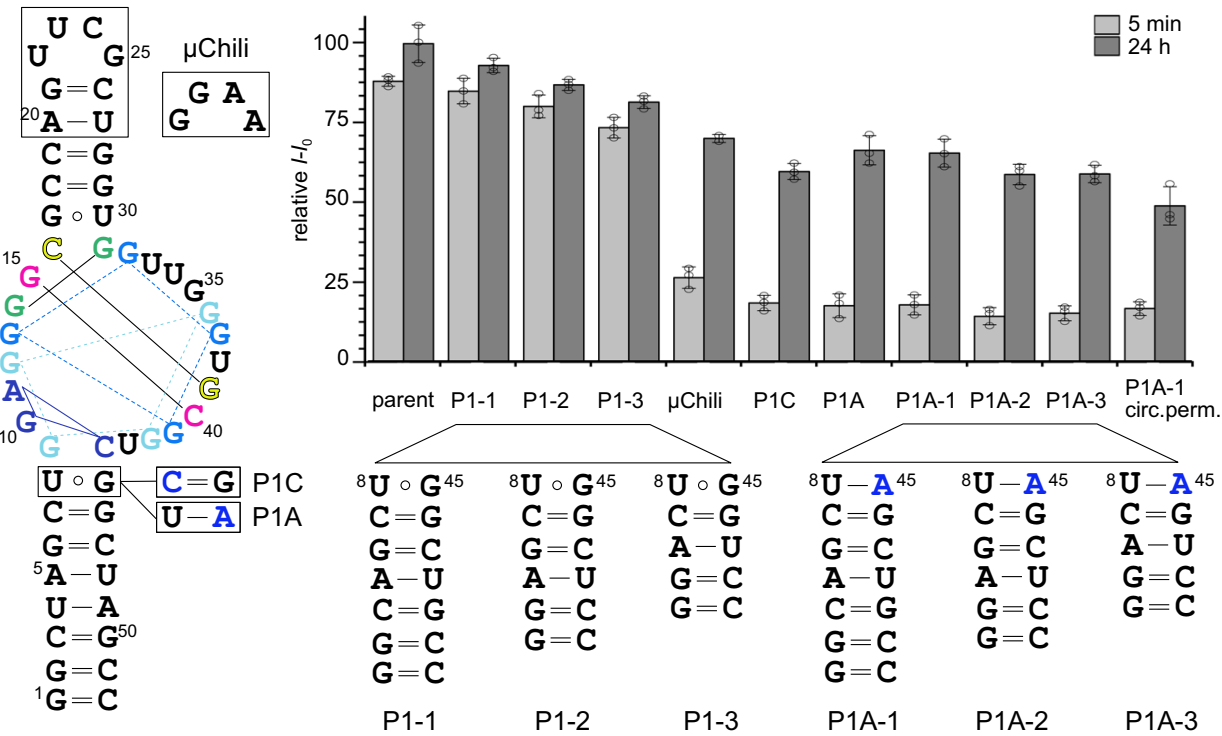

b

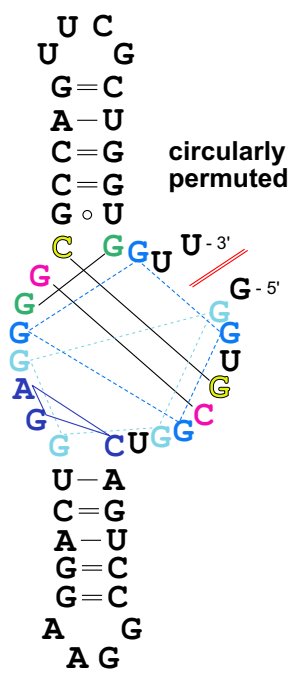

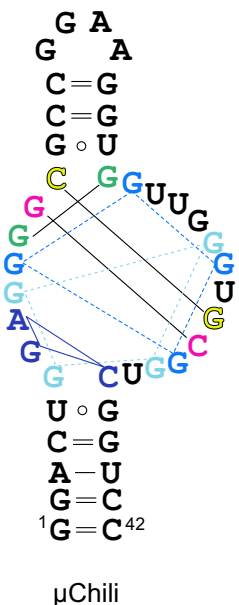
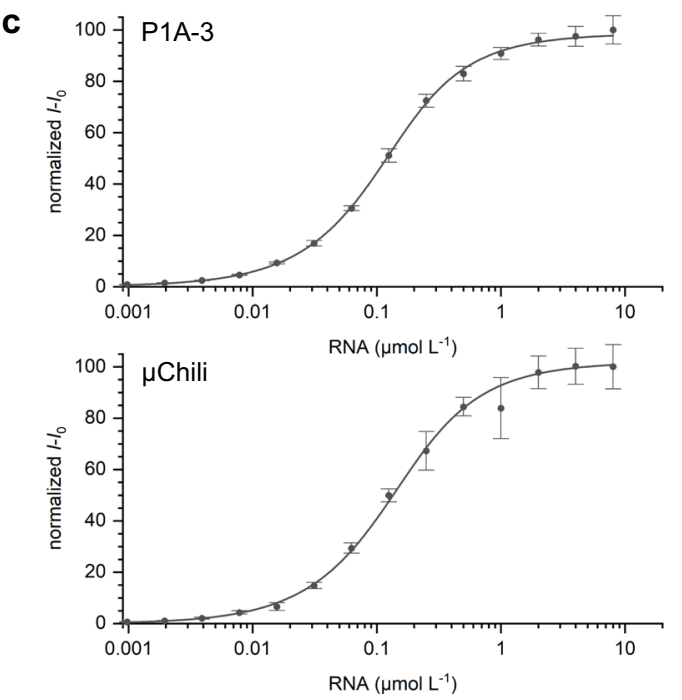

Fig. 5 Minimization and circular permutation of the Chili aptamer. a Mutations and truncation of the stems P1 and P2 of the parent Chili RNA are well tolerated. Fluorescence intensities of the corresponding Chili-DMHBI+ complexes, upon incubation for 5 min and $24 \mathrm{~h}$, relative to the parent complex. (1 $\mu \mathrm{M}$ RNA and ligand). $n=3$ independent experiments, mean \pm SD. b Secondary structures of the circularly permuted Chili aptamer and $\mu$ Chili. c Titration curves of $\mathrm{DMHBI}^{+}(0.1 \mu \mathrm{M})$ with increasing RNA concentration demonstrate tight binding. $K_{\mathrm{D}}=68 \mathrm{nM}$ for P1A-3 and $89 \mathrm{nM}$ for $\mu$ Chili, respectively. Normalized fluorescence intensity is plotted versus RNA concentration. Data were presented as mean values \pm SD ( $n=3$ independent titration experiments).
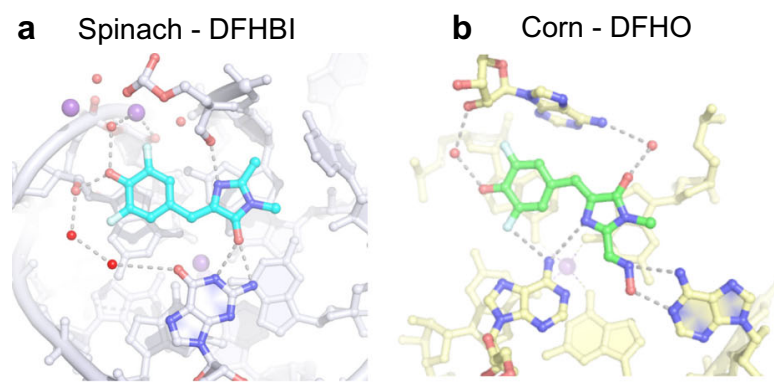

c Chili- $\mathrm{DMHBO}^{+}$

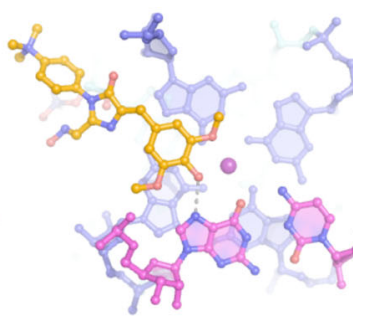

Fig. 6 Comparison of RNA binding sites for HBI analogs in fluorogenic aptamers. a Spinach-DFHBI (pdb 4TSO). b Corn-DFHO (pdb 5BJO). c Chili-DMHBO $+(p d b 7 O A X)$. The ligand is shown on top of the nearest G-quartet and H-bonding interactions to the phenol/phenolate, imidazolone and oxime are indicated. 
purified by $10 \%$ denaturing PAGE, extracted into TEN buffer, and recovered by precipitation with ethanol.

RNAs containing $c^{7} \mathrm{G}$ and $\mathrm{r} 4 \mathrm{CI}$ were prepared by enzymatic ligation of synthetic oligonucleotides obtained by solid phase synthesis using $2^{\prime}-O-T O M-$ protected phosphoramidites under standard conditions ${ }^{28,51}$. The $\mathrm{c}^{7} \mathrm{G}$ phosphoramidite was purchased form ChemGenes, the r4CI phosphoramidite, chemical $5^{\prime}$ phosphorylation reagent, and $3^{\prime}$-phosphate CPG support were prepared as described ${ }^{28}$. Sequence information for RNAs are given in Supplementary Table 2 .

\section{Crystallization of Chili $\mathrm{DMHBI}^{+}$and $\mathrm{DMHBO}^{+}$complexes. Crystallization} complexes were formed by mixing RNA and ligand in a 1:1.2 molar ratio in $10 \mathrm{mM}$ HEPES $\mathrm{pH} 8.0,50 \mathrm{mM} \mathrm{KCl}$, and $1.5 \%$ DMSO. The sample was heated to $95^{\circ} \mathrm{C}$ for $3 \mathrm{~min}$ and cooled at $23^{\circ} \mathrm{C}$ for $30 \mathrm{~min}$. $\mathrm{MgCl}_{2}$ was added to a final concentration of $5 \mathrm{mM}$ and the solution was stored at $4^{\circ} \mathrm{C}$ for $16 \mathrm{~h}$ prior to setting up crystallization drops. The Chili-DMHBI ${ }^{+}$complex was concentrated using Vivaspin 3000 MWCO ultrafiltration spin columns to $\sim 0.5 \mathrm{mM}$ and subjected to crystallization screening at $20^{\circ} \mathrm{C}$. Initial crystals appeared after 1 day. For the crystallization optimization, concentrations of the Chili-DMHBI ${ }^{+}$(Crystal I) and Chili-DMHBO ${ }^{+}$(Crystal II) complexes were reduced to $\sim 0.1 \mathrm{mM}$. Larger single crystals were grown at $20^{\circ} \mathrm{C}$ using the hanging and/or sitting drop vapor-diffusion method by mixing Chili-DMHBI ${ }^{+}$ and Chili-DMHBO ${ }^{+}$complexes with solutions containing 12-17\% PEG 400, $0.1 \mathrm{M}$ MES pH 5.4-5.8, and $12 \mathrm{mM}$ spermine tetrahydrochloride in 1:1 ratio. Drops with volumes of $0.5-2 \mu \mathrm{L}$ produced crystals after 1-2 days and were harvested after 7 days. Prior to data collection, crystals were cryoprotected in the mother liquor containing $30 \%$ glycerol and flash frozen in liquid $\mathrm{N}_{2}$.

Incorporation of heavy metal ions into the crystals was achieved by soaking and by co-crystallization. The co-crystallization with heavy metal was performed at $20^{\circ}$ $\mathrm{C}$ using the sitting drop vapor-diffusion method by mixing Chili-DMHBO ${ }^{+}$ complex with solutions containing 12-17\% PEG 400, 0.1 M MES pH 5.4-5.8, 12 $\mathrm{mM}$ spermine tetrahydrochloride, and $1 \mathrm{mM}$ Iridium(III) hexammine (prepared according to ref. ${ }^{26}$ ) in 1:1 ratio. Prior to data collection, Chili-DMHBO ${ }^{+}$Iridium (III) hexammine co-crystals (Crystal III) were back-soaked in the mother liquor without Iridium(III) hexammine containing $30 \%$ glycerol and flash frozen. Soaking of the crystal was done by transferring native crystal to the mother liquor solution containing $20 \%$ glycerol and $0.1 \mathrm{mM}$ Iridium(III) hexammine (Crystal IV). After $10 \mathrm{~min}$, the crystal was back-soaked in mother liquor solution containing 30\% glycerol and flash frozen in liquid nitrogen.

Data collection and structure determination. Diffraction data were collected at $100 \mathrm{~K}$ on EIGER16 M and PILATUS 6M detectors at the X10SA (Swiss Light Source) or P11 (DESY) beamlines. Data were indexed, integrated, and scaled with $\mathrm{XDS}^{52}$, and reduced with POINTLESS, AIMLESS, and CTRUNCATE within the CCP4 package ${ }^{53}$. Initial phases were determined by single anomalous dispersion (SAD) using AutoSol Wizard in Phenix ${ }^{54}$, with the Crystal III data collected at the Iridium L-III peak wavelength. Electron density map from AutoSol was used for automated model building with AutoBuild module in Phenix ${ }^{55}$. The initial model from AutoBuild was modified by iterative rebuilding in $\mathrm{COOT}^{56}$ and refinement with Phenix.refine ${ }^{57}$. The partially built model from the Crystal III data were used as a MR search model in Phaser against a high resolution native dataset (Crystal II), previously corrected for anisotropy using the STARANISO server ${ }^{58}$. (http:// staraniso.globalphasing.org/cgi-bin/staraniso.cgi). The model was completed by manual rebuilding in COOT and refined to the final $R_{\text {free }}$ value of $23.7 \%$. The location of the $\mathrm{DMHBO}^{+}$ligand was confirmed using both unbiased $\mathrm{mFo}-\mathrm{DFc}$ and polder omit maps ${ }^{59}$. Ligand restraints were prepared using eLBOW in Phenix. The final structures of Crystal I and Crystal IV were solved by MR using a single 51-nt long RNA model built with Crystal II data. Water molecules were added and inspected manually. Data collection and refinement statistics are summarized in Supplementary Table 1. Structure coordinates were deposited in Protein Data Bank with the accession codes: 7OAW, 7OAX, 7OA3, and 7OAV. The structures were analyzed and figures were prepared using PyMol (Schrödinger).

NMR spectroscopy. RNA samples used in NMR experiments were prepared by in vitro transcription as described above. ${ }^{15} \mathrm{~N}$ labeled nucleotides were purchased from Silantes. RNA folding was achieved by thermal denaturation of the RNA at a concentration of $\sim 0.2 \mathrm{mM}$ followed by tenfold dilution with ice cold water and incubation for $1 \mathrm{~h}$ on ice. RNA samples were exchanged with NMR buffer $(25 \mathrm{mM}$ Tris-HCl, pH 7.4) using centrifuge concentrator devices (Vivaspin 3000 MWCO). RNA concentration in the final NMR samples was $\sim 0.5 \mathrm{mM}$. The homogeneity of the folding was checked via $15 \%$ polyacrylamide native gels (acrylamide:bisacrylamide $=29: 1, \mathrm{TBE}$ as running buffer) at room temperature and at a power $\leq 1 \mathrm{~W}$ to avoid overheating. All the samples contained 3-(trimethylsilyl)-1-propanesulfonic acid (DSS) as internal NMR reference and were dissolved in $10 \% \mathrm{D}_{2} \mathrm{O} / 90 \%$ $\mathrm{H}_{2} \mathrm{O} . \mathrm{KCl}\left(50 \mathrm{mM}\right.$ final concentration) and 1 equivalent of $\mathrm{DMHBI}^{+}$(ligand stock solution in $\mathrm{d}_{6}$-DMSO, final concentration of $\mathrm{d}_{6}$-DMSO $\leq 2 \% \mathrm{v} / \mathrm{v}$ ) were added directly into the NMR tube to the folded RNA.

All the NMR experiments were performed on a Bruker Avance III 600 NMR spectrometer equipped with a DCH ${ }^{13} \mathrm{C} /{ }^{1} \mathrm{H}$ cryoprobe or on a Bruker Avance III 600 NMR spectrometer equipped with a BBFO room temperature probe. The
HNN-COSY experiment was performed by Dr. Helena Kovacs at Bruker Biospin (Fällanden, Switzerland) on a Bruker $700 \mathrm{MHz}$ spectrometer equipped with a QCI$\mathrm{P}$ cryoprobe. The spectra were acquired and processed with the software Topspin 3.2 (Bruker BioSpin, Germany). Spectra analysis was performed with the software Sparky 3.114 (Goddard, T. D.; Kneller, D. G. University of California, San Francisco). The ${ }^{1} \mathrm{H},{ }^{15} \mathrm{~N}$-BEST-TROSY experiments were recorded using a pulse program containing the modifications proposed by Brutscher et al ${ }^{60,61}$. and an inter-scan delay of $0.3 \mathrm{~s}$. The HNN-COSY experiment ${ }^{62}$ was recorded using a soft WaterGATE water suppression scheme ${ }^{63}$, an $\mathrm{HN}$ transfer delay of $2.5 \mathrm{~ms}$, and a NN transfer delay of $15 \mathrm{~ms}$.

Steady-state UV/VIS absorption and fluorescence spectroscopy. Steady-state fluorescence spectra were measured in Hellma ultra-micro quartz cuvettes (1.5 $\mathrm{mm} \times 1.5 \mathrm{~mm}, 3 \mathrm{~mm} \times 3 \mathrm{~mm}$, or $10 \mathrm{~mm} \times 2 \mathrm{~mm}$ path lengths) with a JASCO FP8300 spectrofluorometer equipped with an FCT-817S cell changer. Steady-state UV/VIS spectra and melting curves were measured in semi-micro quartz cuvettes (10 mm path length) with a Varian Cary 100 Bio spectrophotometer equipped with a $6 \times 6$ Multicell Block Peltier Series II cell changer and a Varian Cary Temperature Controller.

Samples for UV/VIS and fluorescence spectroscopy were prepared with the indicated concentration of RNA, annealed by heating to $95^{\circ} \mathrm{C}$ for $3 \mathrm{~min}$ and cooling to ambient temperature for $20 \mathrm{~min}$ in binding buffer $(125 \mathrm{mM} \mathrm{KCl}, 40 \mathrm{mM}$ HEPES $\mathrm{pH} 7.5)^{18}$. The indicated concentrations of $\mathrm{DMHBI}^{+}$or $\mathrm{DMHBO}^{+}$ligand and $\mathrm{MgCl}_{2}(5 \mathrm{mM})$ were added. For screening of metal ion conditions, $\mathrm{KCl}$ was replaced by $\mathrm{NaCl}, \mathrm{LiCl}$, or $\mathrm{TlOAc}$, and $\mathrm{MgCl}_{2}$ was replaced by $\mathrm{MnCl}_{2}, \mathrm{BaCl}_{2}$, or $\mathrm{SrCl}_{2}$. For experiments with $\mathrm{Tl}^{+}$, the RNA was precipitated from $\mathrm{NaOAc}$ and desalted via a centrifugal filter (Vivapsin $3000 \mathrm{MWCO}$ ), and $\mathrm{MgCl}_{2}$ was replaced by $\mathrm{Mg}(\mathrm{OAc})_{2}$.

Fluorescence spectra of the samples were measured $5 \mathrm{~min}$ after addition of the ligand and again after an additional incubation period of $24 \mathrm{~h}$ at $4{ }^{\circ} \mathrm{C}$. Samples were excited at $413 \mathrm{~nm}$ (when using $\mathrm{DMHBI}^{+}$) or $456 \mathrm{~nm}$ (when using $\mathrm{DMHBO}^{+}$) and fluorescence emission spectra recorded up to $750 \mathrm{~nm}$. Other instrument parameters (Ex/Em slit widths, scan speed, integration time, and detector sensitivity) were kept constant.

For binding affinity titrations, fluorescence spectra were measured $24 \mathrm{~h}$ after preparation of the individual samples and the emission bands were integrated. The resulting values (mean $\pm \mathrm{SD}$ for $n=3$ ) were fitted to a one-site binding model in OriginPro $2019^{8}$

For melting curve measurements, 5 ramps between 10 and $95^{\circ} \mathrm{C}$ (UV: $0.5^{\circ} \mathrm{C} /$ min, fluorescence: $1^{\circ} \mathrm{C} / \mathrm{min}$ or $5^{\circ} \mathrm{C} / \mathrm{min}$ ) were recorded, the first ramp served for annealing and was not included in the data analysis. The samples were layered with silicon oil to minimize evaporation during the experiment.

Time-resolved spectroscopy. TCSPC measurements were performed on a Horiba DeltaFlex system with a DeltaDiode DD-320 excitation source (time calibration: $0.026 \mathrm{~ns} /$ channel, 4096 channels). The samples were prepared as described above at an RNA concentration of 0.5 and $1 \mu \mathrm{M}$ ligand (in $125 \mathrm{mM} \mathrm{KCl}, 40 \mathrm{mM}$ HEPES $\mathrm{pH}$ 7.5 , and $5 \mathrm{mM} \mathrm{MgCl}_{2}$ ). A sample without RNA and ligand was used to measure the instrument response function (Em wavelength $=$ Ex wavelength). Data analysis was performed with Data Analysis Station 6 (Horiba) by fitting to an appropriate sum of exponentials. Fit quality was judged by the reduced $\chi^{2}$ value $(<1.2$ without improvement due to additional exponential terms) and a random distribution of the residuals.

\section{Broadband fluorescence upconversion (FLUPS) and transient absorption} spectroscopy (TAS). All measurements were performed in 1 or $0.2 \mathrm{~mm}$ quartz cuvettes. The samples were prepared as described above at a complex concentration of 250 or $625 \mu \mathrm{M}$ in $125 \mathrm{mM} \mathrm{KCl}, 40 \mathrm{mM}$ HEPES pH 7.5, and $5 \mathrm{mM} \mathrm{MgCl}_{2}$. Both spectrometers, the broadband fluorescence upconversion, and the transient absorption spectrometer, were driven by a chirped pulse amplified femtosecond laser "Solstice" from Newport-Spectra with a fundamental wavelength of $800 \mathrm{~nm}$, a pulse width of $100 \mathrm{fs}$, and a repetition rate of $1 \mathrm{kHz}$.

The FLUPS is a commercial available spectrometer from LIOPTEC which can simultaneously measure $395-850 \mathrm{~nm}$ fluorescence with an intrinsic resolution of $0.9 \mathrm{~nm}(303-516 \mathrm{~nm}$ upconverted, intrinsic resolution $0.42 \mathrm{~nm})$. The maximum delay between pump and gate pulse can be up to $1.500 \mathrm{ps}$. To generate the pump wavelength $405 \mathrm{~nm}$ for the FLUPS we used the output from a non collinear parametric amplifier which was set to $810 \mathrm{~nm}$. The $810 \mathrm{~nm}$ were guided through a BBO crystal to generate the second harmonic at $405 \mathrm{~nm}$. We used an $800 \mathrm{~nm}$ broadband bandpass filter to eliminate the residual $810 \mathrm{~nm}$. The pump pulse energy was $50 \mathrm{~nJ}$ and the gate pulse energy was $30 \mathrm{uJ}$ at $1280 \mathrm{~nm}$. For more details on the setup see ref. ${ }^{64}$

The pump pulse from the TAS was generated with a traveling wave oscillating parametric amplifier "TOPAS-C" from Light Conversion. The pump pulse energy was set to $40 \mathrm{~nJ}$. The white light was generated with a moving $\mathrm{CaF}_{2}$ crystal with some filters to achieve a probe light from 400 to $800 \mathrm{~nm}$. The maximum delay between pump and probe was $8 \mathrm{~ns}$. For a more detailed description of the setup see ref. ${ }^{65}$. 
For both types of measurement we performed a global analysis of the data using GLOTARAN software ${ }^{66}$. This analysis takes the white light dispersion and, in case of the TA measurements, the coherent artifact into account and yields evolution associated difference spectra (EADS) for a consecutive kinetic model and decay associated difference spectra (DADS) for a parallel kinetic model ${ }^{67}$.

Reporting summary. Further information on experimental design is available in the Nature Research Reporting Summary linked to this paper.

\section{Data availability}

Structural data obtained by X-ray crystallography were deposited in the Protein Data Bank (PDB) and are available with the following accession codes: 7OAW, 7OAX, 7OA3, $7 \mathrm{OAV}$. All relevant data are provided in the Figures and Supplementary Information (Supplementary Figs. 1-20). Publicly available datasets used in this study: PDB 3NT9, 4TS0, 5BJO, 6XWY. Source data are provided with this paper.

Received: 23 February 2021; Accepted: 25 May 2021; Published online: 10 June 2021

\section{References}

1. Trachman, R. J. \& Ferre-D'Amare, A. R. Tracking RNA with light: selection, structure, and design of fluorescence turn-on RNA aptamers. Q Rev. Biophys. 52, e8 (2019).

2. Jaffrey, S. R. RNA-based fluorescent biosensors for detecting metabolites in vitro and in living cells. Adv. Pharm. 82, 187-203 (2018).

3. Bouhedda, F., Autour, A. \& Ryckelynck, M. Light-up RNA aptamers and their cognate fluorogens: from their development to their applications. Int. J. Mol. Sci. 19, https://doi.org/10.3390/ijms19010044 (2017).

4. Babendure, J. R., Adams, S. R. \& Tsien, R. Y. Aptamers switch on fluorescence of triphenylmethane dyes. J. Am. Chem. Soc. 125, 14716-14717 (2003).

5. Paige, J. S., Wu, K. Y. \& Jaffrey, S. R. RNA mimics of green fluorescent protein. Science 333, 642-646 (2011).

6. Filonov, G. S., Moon, J. D., Svensen, N. \& Jaffrey, S. R. Broccoli: rapid selection of an RNA mimic of green fluorescent protein by fluorescence-based selection and directed evolution. J. Am. Chem. Soc. 136, 16299-16308 (2014).

7. Warner, K. D. et al. A homodimer interface without base pairs in an RNA mimic of red fluorescent protein. Nat. Chem. Biol. 13, 1195-1201 (2017).

8. Steinmetzger, C., Palanisamy, N., Gore, K. R. \& Höbartner, C. A multicolor large stokes shift fluorogen-activating RNA aptamer with cationic chromophores. Chem. Eur. J. 25, 1931-1935 (2019).

9. Dolgosheina, E. V. et al. RNA mango aptamer-fluorophore: a bright, highaffinity complex for RNA labeling and tracking. ACS Chem. Biol. 9, 2412-2420 (2014).

10. Wirth, R., Gao, P., Nienhaus, G. U., Sunbul, M. \& Jäschke, A. SiRA: a silicon rhodamine-binding aptamer for live-cell super-resolution RNA imaging. J. Am. Chem. Soc. 141, 7562-7571 (2019).

11. Bouhedda, F. et al. A dimerization-based fluorogenic dye-aptamer module for RNA imaging in live cells. Nat. Chem. Biol. 16, 69-76 (2020).

12. Chen, X. et al. Visualizing RNA dynamics in live cells with bright and stable fluorescent RNAs. Nat. Biotechnol. 37, 1287-1293 (2019).

13. Niwa, H. et al. Chemical nature of the light emitter of the Aequorea green fluorescent protein. Proc. Natl Acad. Sci. USA 93, 13617-13622 (1996).

14. Song, W., Strack, R. L., Svensen, N. \& Jaffrey, S. R. Plug-and-play fluorophores extend the spectral properties of Spinach. J. Am. Chem. Soc. 136, 1198-1201 (2014).

15. Li, X., Kim, H., Litke, J. L., Wu, J. \& Jaffrey, S. R. Fluorophore-promoted RNA folding and photostability enables imaging of single broccoli-tagged mRNAs in live mammalian cells. Angew. Chem. Int. Ed. 59, 4511-4518 (2020).

16. Cormack, B. P., Valdivia, R. H. \& Falkow, S. FACS-optimized mutants of the green fluorescent protein (GFP). Gene 173, 33-38 (1996).

17. Miyawaki, A., Shcherbakova, D. M. \& Verkhusha, V. V. Red fluorescent proteins: chromophore formation and cellular applications. Curr. Opin. Struct. Biol. 22, 679-688 (2012).

18. Steinmetzger, C., Bessi, I., Lenz, A. K. \& Höbartner, C. Structure-fluorescence activation relationships of a large Stokes shift fluorogenic RNA aptamer. Nucleic Acids Res. 47, 11538-11550 (2019).

19. Piatkevich, K. D., Malashkevich, V. N., Almo, S. C. \& Verkhusha, V. V. Engineering ESPT pathways based on structural analysis of LSSmKate red fluorescent proteins with large Stokes shift. J. Am. Chem. Soc. 132, 10762-10770 (2010).

20. Warner, K. D. et al. Structural basis for activity of highly efficient RNA mimics of green fluorescent protein. Nat. Struct. Mol. Biol. 21, 658-663 (2014).

21. Huang, $\mathrm{H}$. et al. A G-quadruplex-containing RNA activates fluorescence in a GFP-like fluorophore. Nat. Chem. Biol. 10, 686-691 (2014).
22. Fernandez-Millan, P., Autour, A., Ennifar, E., Westhof, E. \& Ryckelynck, M. Crystal structure and fluorescence properties of the iSpinach aptamer in complex with DFHBI. RNA 23, 1788-1795 (2017).

23. Trachman, R. J. 3rd et al. Structural basis for high-affinity fluorophore binding and activation by RNA Mango. Nat. Chem. Biol. 13, 807-813 (2017).

24. Trachman, R. J. 3rd et al. Crystal structures of the Mango-II RNA aptamer reveal heterogeneous fluorophore binding and guide engineering of variants with improved selectivity and brightness. Biochemistry 57, 3544-3548 (2018)

25. Trachman, R. J. 3rd et al. Structure and functional reselection of the MangoIII fluorogenic RNA aptamer. Nat. Chem. Biol. 15, 472-479 (2019).

26. Batey, R. T. \& Kieft, J. S. Soaking hexammine cations into RNA crystals to obtain derivatives for phasing diffraction data. Methods Mol. Biol. 1320, 219-232 (2016)

27. Ennifar, E. et al. The crystal structure of UUCG tetraloop. J. Mol. Biol. 304, 35-42 (2000).

28. Steinmetzger, C., Bäuerlein, C. \& Höbartner, C. Supramolecular fluorescence resonance energy transfer in nucleobase-modified fluorogenic RNA aptamers. Angew. Chem. Int. Ed. 59, 6760-6764 (2020).

29. Truong, J., Hsieh, Y. F., Truong, L., Jia, G. \& Hammond, M. C. Designing fluorescent biosensors using circular permutations of riboswitches. Methods 143, 102-109 (2018).

30. Litke, J. L., You, M. \& Jaffrey, S. R. Developing fluorogenic riboswitches for imaging metabolite concentration dynamics in bacterial cells. Methods Enzymol. 572, 315-333 (2016).

31. Liu, D. et al. Branched kissing loops for the construction of diverse RNA homooligomeric nanostructures. Nat. Chem. 12, 249-259 (2020).

32. Jepsen, M. D. E. et al. Development of a genetically encodable FRET system using fluorescent RNA aptamers. Nat. Commun. 9, 18 (2018).

33. Shelke, S. A. et al. Structural basis for activation of fluorogenic dyes by an RNA aptamer lacking a G-quadruplex motif. Nat. Commun. 9, 4542 (2018).

34. Laptenok, S. P. et al. Photoacid behaviour in a fluorinated green fluorescent protein chromophore: ultrafast formation of anion and Zwitterion states. Chem. Sci. 7, 5747-5752 (2016).

35. Han, K. Y., Leslie, B. J., Fei, J., Zhang, J. \& Ha, T. Understanding the photophysics of the spinach-DFHBI RNA aptamer-fluorogen complex to improve live-cell RNA imaging. J. Am. Chem. Soc. 135, 19033-19038 (2013).

36. Wang, P. C. et al. Photochemical properties of Spinach and its use in selective imaging. Chem. Sci. 4, 2865-2873 (2013).

37. Erdogan, M., Fabritius, A., Basquin, J. \& Griesbeck, O. Targeted in situ protein diversification and intra-organelle validation in mammalian cells. Cell Chem. Biol. 27, 610-621 (2020). e615.

38. Micura, R. \& Höbartner, C. Fundamental studies of functional nucleic acids aptamers, riboswitches, ribozymes and DNAzymes. Chem. Soc. Rev. 49, 7331-7353 (2020)

39. Battaglia, R. A. \& Ke, A. Guanidine-sensing riboswitches: how do they work and what do they regulate? Wiley Interdiscip. Rev. RNA https://doi.org/ 10.1002/wrna.1482 (2018)

40. Meech, S. R. Excited state reactions in fluorescent proteins. Chem. Soc. Rev. 38 , 2922-2934 (2009).

41. Chattoraj, M., King, B. A., Bublitz, G. U. \& Boxer, S. G. Ultra-fast excited state dynamics in green fluorescent protein: multiple states and proton transfer. Proc. Natl Acad. Sci. USA 93, 8362-8367 (1996).

42. Kondo, M., Heisler, I. A., Stoner-Ma, D., Tonge, P. J. \& Meech, S. R. Ultrafast dynamics of protein proton transfer on short hydrogen bond potential energy surfaces: S65T/H148D GFP. J. Am. Chem. Soc. 132, 1452-1453 (2010).

43. Kennis, J. T., van Stokkum, I. H., Peterson, D. S., Pandit, A. \& Wachter, R. M. Ultrafast proton shuttling in Psammocora cyan fluorescent protein. J. Phys. Chem. B 117, 11134-11143 (2013).

44. Shi, X. et al. Ultrafast excited-state dynamics in the green fluorescent protein variant S65T/H148D. 2. Unusual photophysical properties. Biochemistry 46, 12014-12025 (2007)

45. Romei, M. G., Lin, C. Y., Mathews, I. I. \& Boxer, S. G. Electrostatic control of photoisomerization pathways in proteins. Science 367, 76-79 (2020).

46. Laptenok, S. P. et al. Infrared spectroscopy reveals multi-step multi-timescale photoactivation in the photoconvertible protein archetype dronpa. Nat. Chem. 10, 845-852 (2018).

47. Ageely, E. A., Kartje, Z. J., Rohilla, K. J., Barkau, C. L. \& Gagnon, K. T. Quadruplex-Flanking Stem Structures Modulate the Stability and Metal Ion Preferences of RNA Mimics of GFP. ACS Chem. Biol. 11, 2398-2406 (2016).

48. Ketterer, S., Fuchs, D., Weber, W. \& Meier, M. Systematic reconstruction of binding and stability landscapes of the fluorogenic aptamer spinach. Nucleic Acids Res. 43, 9564-9572 (2015).

49. Savage, J. C., Davare, M. A. \& Shinde, U. Subtle sequence variations alter tripartite complex kinetics and G-quadruplex dynamics in RNA aptamer Broccoli. Chem. Commun. 56, 2634-2637 (2020).

50. Rio, D. C. Expression and purification of active recombinant T7 RNA polymerase from E. coli. Cold Spring Harb. Protoc. https://doi.org/10.1101/ pdb.prot078527 (2013). 
51. Höbartner, C. et al. The synthesis of 2'-O-[(Triisopropylsilyl)oxy] methyl (TOM) phosphoramidites of methylated ribonucleosides $\left(\mathrm{m}^{1} \mathrm{G}, \mathrm{m}^{2} \mathrm{G}, \mathrm{m}^{2} \mathrm{G}\right.$, $\mathrm{m}^{1} \mathrm{I}, \mathrm{m}^{3} \mathrm{U}, \mathrm{m}^{4} \mathrm{C}, \mathrm{m}^{6} \mathrm{~A}, \mathrm{~m}^{6} \mathrm{~A}$ ) for use in automated RNA solid-phase synthesis. Monatsh. Chem. 134, 851-873 (2003).

52. Kabsch, W. Xds. Acta Crystallogr. D. Biol. Crystallogr. 66, 125-132 (2010).

53. Evans, P. R. An introduction to data reduction: space-group determination, scaling and intensity statistics. Acta Crystallogr. D. Biol. Crystallogr. 67, 282-292 (2011).

54. Adams, P. D. et al. PHENIX: a comprehensive Python-based system for macromolecular structure solution. Acta Crystallogr. D. Biol. Crystallogr. 66, 213-221 (2010).

55. Terwilliger, T. C. et al. Iterative model building, structure refinement and density modification with the PHENIX AutoBuild wizard. Acta Crystallogr. D. Biol. Crystallogr. 64, 61-69 (2008).

56. Emsley, P. \& Cowtan, K. Coot: model-building tools for molecular graphics. Acta Crystallogr. D. Biol. Crystallogr. 60, 2126-2132 (2004).

57. Afonine, P. V. et al. Towards automated crystallographic structure refinement with phenix.refine. Acta Crystallogr. D. Biol. Crystallogr. 68, 352-367 (2012)

58. Vonrhein, C. et al. Advances in automated data analysis and processing within autoPROC, combined with improved characterisation, mitigation and visualisation of the anisotropy of diffraction limits using STARANISO. Acta Crystallogr. A 74, A360-A360 (2018).

59. Liebschner, D. et al. Polder maps: improving OMIT maps by excluding bulk solvent. Acta Crystallogr. D. Struct. Biol. 73, 148-157 (2017).

60. Favier, A. \& Brutscher, B. Recovering lost magnetization: polarization enhancement in biomolecular NMR. J. Biomol. NMR 49, 9-15 (2011).

61. Lescop, E., Kern, T. \& Brutscher, B. Guidelines for the use of band-selective radiofrequency pulses in hetero-nuclear NMR: example of longitudinalrelaxation-enhanced BEST-type $1 \mathrm{H}-15 \mathrm{~N}$ correlation experiments. J. Magn. Reson. 203, 190-198 (2010).

62. Dingley, A. J. \& Grzesiek, S. Direct observation of hydrogen bonds in nucleic acid base pairs by internucleotide (2)J(NN) couplings. J. Am. Chem. Soc. 120, 8293-8297 (1998).

63. Piotto, M., Saudek, V. \& Sklenar, V. Gradient-tailored excitation for singlequantum NMR spectroscopy of aqueous solutions. J. Biomol. NMR 2, 661-665 (1992).

64. Hattori, Y. et al. Luminescent mono-, di-, and triradicals: bridging polychlorinated triarylmethyl radicals by triarylamines and triarylboranes. Chemistry 25, 15463-15471 (2019).

65. Auerhammer, N. et al. Dynamic exciton localisation in a pyrene-BODIPYpyrene dye conjugate. Phys. Chem. Chem. Phys. 21, 9013-9025 (2019).

66. Snellenburg, J. J., Laptenok, S. P., Seger, R., Mullen, K. M. \& van Stokkum, I. H. M. Glotaran: a java-based graphical user interface for the R package TIMP. J. Stat. Softw. 49, 1-22 (2012).

67. van Stokkum, I. H., Larsen, D. S. \& van Grondelle, R. Global and target analysis of time-resolved spectra. Biochim. Biophys. Acta 1657, 82-104 (2004).

\section{Acknowledgements}

This work was supported by the European Research Council (ERC/No 682586), the Deutsche Forschungsgemeinschaft (DFG), the Max Planck Society, the University of
Würzburg, and the SolTech Initiative of the Bavarian State Ministry of Education, Culture, Science, and the Arts. We thank Ulrich Steuerwald and Jürgen Wawrzinek for technical assistance in the crystallization facility (MPI for biophysical chemistry), Matthias Grüne (University Würzburg) and Helena Kovacs (Bruker BioSpin AG) for NMR support, Matthias Stolte (University Würzburg) for the fluorescent images of crystals, and the beamline staff at DESY (PETRA III, P11) and at the Swiss Light Source PSI (PXII) for assistance with data collection.

\section{Author contributions}

M.M., C.S., I.B., and C.H. designed the study, M.M. crystallized the complexes and solved the structure under the supervision of V.P.; TA and FLUPS experiments were performed by A.S. and analysed by M.H. and C.L.; all other experiment were performed by C.S., I.B., A.-K.L. and C.H. All authors contributed to writing the manuscript.

\section{Funding}

Open Access funding enabled and organized by Projekt DEAL.

\section{Competing interests}

The authors declare no competing interests.

\section{Additional information}

Supplementary information The online version contains supplementary material available at https://doi.org/10.1038/s41467-021-23932-0.

Correspondence and requests for materials should be addressed to C.L., V.P. or C.Höb.

Peer review information Nature Communications thanks Robert Trachman and the other, anonymous, reviewer(s) for their contribution to the peer review of this work. Peer reviewer reports are available.

Reprints and permission information is available at http://www.nature.com/reprints

Publisher's note Springer Nature remains neutral with regard to jurisdictional claims in published maps and institutional affiliations.

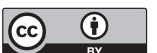

Open Access This article is licensed under a Creative Commons Attribution 4.0 International License, which permits use, sharing, adaptation, distribution and reproduction in any medium or format, as long as you give appropriate credit to the original author(s) and the source, provide a link to the Creative Commons license, and indicate if changes were made. The images or other third party material in this article are included in the article's Creative Commons license, unless indicated otherwise in a credit line to the material. If material is not included in the article's Creative Commons license and your intended use is not permitted by statutory regulation or exceeds the permitted use, you will need to obtain permission directly from the copyright holder. To view a copy of this license, visit http://creativecommons.org/ licenses/by/4.0/

(C) The Author(s) 2021 